\title{
The roles of vitamins $D$ and $K$ in bone health and osteoporosis prevention
}

\author{
BY M. J. SHEARER
}

The Vitamin K Research Unit, The Haemophilia Centre, St Thomas's Hospital, Lambeth Palace Road, London SE1 7EH

Vitamins $\mathrm{D}$ and $\mathrm{K}$ are two fat-soluble vitamins that play different but essential roles in bone metabolism. Vitamin $\mathrm{D}$, after its conversion to a dihydroxylated metabolite, acts as a classical steroid hormone that regulates the transcription of manifold target genes involved with $\mathrm{Ca}$ homeostasis in general and bone mineralization in particular. The role of vitamin $\mathrm{D}$ in promoting mineralization of bone has of course been appreciated for many years, together with the deficiency syndromes of rickets and osteomalacia that result from prolonged deficiency states in childhood and adulthood respectively. Vitamin $\mathrm{K}$, on the other hand, is a cofactor for a carboxylase enzyme that resides in several tissues and promotes the post-translational carboxylation of a number of specialized proteins with $\mathrm{Ca}$ binding properties. They include at least three osteoblastic bone proteins whose functions remain unclear. The synthesis of the best studied vitamin K-dependent bone protein osteocalcin is also regulated by vitamin $\mathrm{D}$. This protein is also one of the ten most abundant vertebrate proteins and represents an interesting point of convergence of the different actions of vitamins $D$ and $K$.

Osteoporosis is a condition characterized by a low bone mass and microarchitectural deterioration of bone tissue that results in an increased bone fragility and increased fracture susceptibility. Neither the nature of osteoporosis (Marcus, 1996) nor its relationship to nutrition in the broad sense (Heaney, 1996; Prentice, 1997) will be considered here. Instead the nutrition and biochemistry of vitamins $D$ and $K$ will be outlined, followed by a consideration of the possible roles of each micronutrient in the pathogenesis and prevention of osteoporosis. If osteoporosis is viewed as being inseparably bound to the normal ageing process, then in the context of the present article it is obviously important to consider the consequences of any ageing process to the nutrition and metabolism of vitamins $\mathrm{D}$ and $\mathrm{K}$. There is evidence of age-related changes for both vitamins that may be relevant to osteoporosis. Finally, an important question to consider is whether nutritional or pharmacological supplementation with vitamins $\mathrm{D}$ and $\mathrm{K}$ may prove to be of benefit to the treatment and prophylaxis of osteoporosis.

One potentially exciting area will be omitted and this is the question of gene-nutrient interactions and particularly how polymorphisms of the vitamin D-receptor (VDR) gene might affect bone mineral density (BMD). The main reason for this omission is that the results in this rapidly-moving field are presently in conflict (Houston et al. 1996). Another intriguing hypothesis linking lipoprotein-mediated vitamin $\mathrm{K}$ transport and polymorphisms of apolipoprotein $\mathrm{E}$ to bone integrity also needs further work (Kohlmeier et al. 1996).

\section{VITAMIN D: SOURCES OF VITAMIN D}

\section{Photosynthesis of vitamin $D$ in human skin}

The importance of sunshine exposure for vitamin D synthesis by the skin is well known. Less well known, until the recent work of Holick's group in Boston, have been the quantitative aspects of the skin photochemistry and the associated environmental factors that together have a practical impact on vitamin D status (for review, see Holick, 1995). As 
much as $80-90 \%$ of the body's stores of vitamin D may come from casual exposure to sunlight. However, in northern climes, photoproduction in the skin is a very seasonal phenomenon limited to the summer months. Thus, only u.v. B photons with energies between 290 and $315 \mathrm{~nm}$ are able to penetrate the skin and reach the epidermal and dermal stores of 7-dehydrocholesterol (procholecalciferol). 7-Dehydrocholesterol is both the immediate precursor for cholesterol (so the skin stores are plentiful) and is photolabile. It is the latter property that is harnessed by the skin and results in the photolytic bond splitting of 7-dehydrocholesterol to precholecalciferol. Precholecalciferol is unstable and undergoes a membrane-enhanced isomerization to cholecalciferol that binds to the vitamin D-binding protein and enters the circulation. In northerly latitudes the quantitative conversion of 7dehydrocholesterol to precholecalciferol has been shown to decline markedly in winter such that in Boston, USA $\left(42^{\circ} \mathrm{N}\right)$ there is no detectable production of precholecalciferol between November and February (Holick, 1995). As discussed later, the seasonality of vitamin D status in places well away from the equator may have important consequences to bone health.

\section{Dietary sources}

The only rich dietary sources of vitamin D as cholecalciferol are fatty fish such as herrings (Clupea harengus), mackerel (Scomber scombrus), pilchards (Sardina pilchardus), sardines and tuna (Thunnus albacares), but these are rarely major contributors to the diet. Other useful sources are eggs and, depending on the country, fortified foods such as milk, yoghurts, margarines and breakfast cereals. The other naturally-occurring form of vitamin D, ergocalciferol, occurs in plants and fungi (produced by u.v. irradiation of ergosterol) but makes little impact as a dietary source except where this compound is used instead of cholecalciferol to fortify foods. The average daily dietary consumption of vitamin D in the UK is about $3 \mu \mathrm{g}$ (Ministry of Agriculture Fisheries and Food, 1994) and similar intakes pertain to the USA (Dawson-Hughes et al. 1995). In the UK, current recommendations (Department of Health, 1991) are that only people aged over 65 years need an extra dietary source ( $10 \mu \mathrm{g}$ daily) but this is under review.

\section{METABOLISM AND ACTIONS OF VITAMIN D}

\section{Metabolic events leading to the biologically-active form of vitamin $D$}

Whether derived from skin synthesis or the diet, vitamin D only becomes biologically active after two sequential tissue hydroxylation reactions. The first hydroxylation reaction is carried out by the liver and results in the production of the major transport form 25hydroxyvitamin $\mathrm{D}(25(\mathrm{OH}) \mathrm{D})$ while the second is carried out by the kidney and results in the active hormonal form 1,25-dihydroxyvitamin $\mathrm{D}\left(1,25(\mathrm{OH})_{2} \mathrm{D}\right)$. The same metabolic hydroxylations apply to both cholecalciferol and to ergocalciferol, but normally the major hydroxylated metabolites in the body are 25-hydroxycholecalciferol and 1,25-dihydroxycholecalciferol, reflecting the predominance of skin-produced cholecalciferol as the original source. Once formed in the kidney, $1,25(\mathrm{OH})_{2} \mathrm{D}$ is re-secreted into the circulation and is delivered to those target tissues with cells that possess a specific nuclear VDR. In each target cell, the $1,25(\mathrm{OH})_{2} \mathrm{D}$ binds to the VDR to form a complex that binds to regulatory sequences in the upstream region of genes that are regulated by $1,25(\mathrm{OH})_{2} \mathrm{D}$ (Hannah \& Norman, 1994). The major target tissues are the intestine and bone where the biological responses to $1,25(\mathrm{OH})_{2} \mathrm{D}$ are an increase in $\mathrm{Ca}$ absorption and $\mathrm{Ca}$ mobilization respectively. 


\section{Biological actions of 1,25-dihydroxyvitamin $D$ on bone mineralization and remodelling}

The best known and perhaps most important physiological means by which vitamin D affects and maintains bone mineralization is to ensure adequate concentrations of $\mathrm{Ca}$ and phosphate in the circulation and extracellular fluid space. This is demonstrated by the correction of the mineralization defect in a child with hereditary resistance to $1,25(\mathrm{OH})_{2} \mathrm{D}$ by long-term, nocturnal infusions with $\mathrm{Ca}$ and phosphate (Balsan et al. 1986) and by several similar studies in vitamin D-deficient rats (see Bikle, 1994; Holick, 1996).

$1,25(\mathrm{OH})_{2} \mathrm{D}$ also has direct effects on bone in vitro that may be of physiological consequence to bone mineralization. Unravelling the direct effects of $1,25(\mathrm{OH})_{2} \mathrm{D}$ on bone remodelling is complicated by its apparent action on several cell types and the fact that the response is dependent on the stage of differentiation of the bone cell (Feldman et al. 1996).

The bone-forming osteoblasts express the VDR and $1,25(\mathrm{OH})_{2} \mathrm{D}$ regulates the synthesis of several osteoblast gene products that play a role in bone matrix formation and mineralization. These include collagen, alkaline phosphatase (EC 3.1.3.1), osteopontin and the two vitamin K-dependent proteins osteocalcin and matrix Gla protein (MGP). The level of expression of gene products such as osteocalcin that are regulated by $1,25(\mathrm{OH})_{2} \mathrm{D}$ can range from down-regulation in proliferating immature osteoblasts to up-regulation in mature osteoblasts (Lian \& Stein, 1996). The wide-ranging capacity of $1,25(\mathrm{OH})_{2} \mathrm{D}$ to induce differentiation is seen by its ability to stimulate the differentiation of osteoblasts from immature, proliferating cells to fully-differentiated, non-dividing cells that possess the capacity to synthesize matrix proteins and to mineralize bone.

A well-established humoral effect of $1,25(\mathrm{OH})_{2} \mathrm{D}$ on bone is the stimulation of osteoclast-mediated bone resorption both in vivo and in vitro (Teitelbaum et al. 1996). When $1,25(\mathrm{OH})_{2} \mathrm{D}$ is added to organ cultures there is an increase in bone resorption accompanied, amongst other effects, by an increase in osteoclast number and activity. Apparent paradoxes of this effect are that isolated mature osteoclasts fail to respond to $1,25(\mathrm{OH})_{2} \mathrm{D}$ unless co-cultured with osteoblasts and that fully-differentiated osteoclasts do not possess a VDR. The increase in resorptive activity of mature osteoclasts associated with $1,25(\mathrm{OH})_{2} \mathrm{D}$ is thought, therefore, to be indirect and mediated via the osteoblast.

Besides promoting the activation of osteoclasts, $1,25(\mathrm{OH})_{2} \mathrm{D}$ also promotes their differentiation from mononucleated precursors. This action of $1,25(\mathrm{OH})_{2} \mathrm{D}$ on osteoclastogenesis is complex and the steroid hormone regulates both osteoclast precursors and modulatory bone-marrow stromal cells (Suda et al. 1992; Teitelbaum et al. 1996).

\section{ASSESSMENT OF VITAMIN D STATUS}

The simplest and most widely used biochemical marker of vitamin $\mathrm{D}$ status is the level of circulating $25(\mathrm{OH}) \mathrm{D}$. Major advantages are that $25(\mathrm{OH}) \mathrm{D}$ is mainly confined to the extracellular compartment, circulates tightly bound to the vitamin D-binding protein and has a very long half-life. As the first metabolite formed in the liver from vitamin $D$, the plasma pool of $25(\mathrm{OH}) \mathrm{D}$ represents a stable reservoir of a metabolite that lies between the synthesis or intake of vitamin D and its utilization as a hormone. Although responsive to the balance between synthesis or intake and utilization, like other vitamin assays it is difficult to define precise cut-off points to differentiate between a normal and abnormal vitamin D status (Bouillon, 1990; Lips, 1994). A major complication in defining population reference values is the dependence of serum $25(\mathrm{OH}) \mathrm{D}$ on sunshine exposure resulting in geographical and seasonal variability. For individuals it is obviously more straightforward in the clinical arena to define an overt deficiency that will lead to rickets or osteomalacia 
than to define or detect a sub-clinical vitamin D-deficient state that may over a prolonged period of time exert more subtle adverse effects on the skeleton.

\section{VITAMIN D AND OSTEOPOROSIS}

In a review of vitamin D in bone health in the elderly, Parfitt et al. (1982) wrote 'Potentially much more important from the standpoint of public health (i.e. than osteomalacia) is the question of whether sub-clinical vitamin $D$ deficiency can play a role in the pathogenesis of osteoporosis in the elderly and so contribute to the increasing incidence of hip fractures'. They went on to state 'It is surprising how often this possibility is ignored'. In discussing the mechanisms of how this might occur, Parfitt et al. (1982) highlighted the relationship between vitamin D deficiency and secondary hyperparathyroidism in the elderly that they argued could cause accelerated loss of bone by increasing bone turnover. Fifteen years later on, with our correspondingly greater understanding of the interplay between nutritional, metabolic, and genetic factors that together govern the supply and effectiveness of vitamin D in exerting its biological actions on target tissues, there is a much greater appreciation of the pathogenic role of vitamin D deficiency in osteoporosis and how this may indeed be mediated through parathyroid function (see Table 1).

Vitamin D plays a central and lifelong role in bone remodelling and there is now good evidence that age-associated changes in several aspects of its synthesis, absorption, and metabolism may be deleterious to bone health. Individually such changes may be considered relatively minor and often may be a normal consequence of ageing. However, when working in concert over many years, they may lead to significant bone losses, either directly or indirectly by causing alterations in an interacting system one or more steps removed. These changes and their consequences are now discussed in detail.

\section{Effect of ageing on vitamin $D$ status}

Measurements of $25(\mathrm{OH}) \mathrm{D}$ in population studies have been useful in studying the determinants of vitamin D status and how this may change with ageing. Lund \& Sørensen (1979) found that $25(\mathrm{OH}) \mathrm{D}$ levels were significantly higher in younger (18-60 years)

Table 1. Possible sequence of events from suboptimal vitamin D status to osteoporosis and exacerbating factors in elderly subjects

\begin{tabular}{|c|c|c|}
\hline Event & Leads to & Consequence \\
\hline $\begin{array}{l}\text { Sunshine exposure or } \\
\text { dietary vitamin D intake } \downarrow\end{array}$ & Serum $25(\mathrm{OH}) \mathrm{D} \downarrow$ & Impaired vitamin D status \\
\hline Serum $25(\mathrm{OH}) \mathrm{D} \downarrow$ & Serum $1,25(\mathrm{OH})_{2} \mathrm{D} \downarrow$ & Deficiency of active hormone \\
\hline Deficiency of active hormone & $\begin{array}{l}\text { Ca absorption } \downarrow \\
\quad(\text { Serum } \mathrm{Ca} \downarrow \text { serum } \mathrm{P} \uparrow)\end{array}$ & Negative Ca balance \\
\hline Negative $\mathrm{Ca}$ balance & Parathyroid hormone $\uparrow$ & Secondary hyperparathyroidism \\
\hline Secondary hyperparathyroidism & Bone turnover $\uparrow$ & Bone loss $\uparrow$ and osteoporosis \\
\hline \multicolumn{3}{|c|}{$\begin{array}{l}\text { Exacerbating factors in elderly } \\
\text { Impaired skin synthesis of vitamin D } \\
\text { Impaired renal function and/or specific renal synthesis of } 1,25(\mathrm{OH})_{2} \mathrm{D} \\
\text { Decreased number of vitamin D receptors and/or organ resistance }\end{array}$} \\
\hline
\end{tabular}


compared with older (61-93 years) subjects but the correlation between $25(\mathrm{OH}) \mathrm{D}$ and age was only seen in the summer months.

There are several reasons why the elderly may have reduced circulating levels of $25(\mathrm{OH}) \mathrm{D}$ that may be indicative of a suboptimal vitamin D status. One reason is that the elderly, voluntarily or involuntarily, generally have less exposure to sunlight. Another reason is that there is a marked age-dependent decrease in the epidermal concentrations of the vitamin D precursor, 7-dehydrocholesterol (MacLaughlin \& Holick, 1985). The ensuing decreased synthesis of vitamin $D$ has been shown experimentally by comparing plasma vitamin D levels in young (22-30 years) and elderly (62-80 years) subjects in response to the same dose of skin irradiation (Holick et al. 1989). Maximal concentrations of vitamin D occurred after about $24 \mathrm{~h}$ and were threefold lower in the older group than the younger group $(22 v .78 \mathrm{nmol} / \mathrm{l})$. Although a reduction in skin synthesis is probably the most important reason for the lowered vitamin D status of the elderly (Compston, 1995), this may be exacerbated by a less-efficient intestinal absorption of vitamin D (Barragry et al. 1978) and by lower dietary intakes.

Even though the elderly may have a reduced capacity for vitamin D synthesis, they still are able to increase their tissue stores and, hence, benefit from regular sunlight exposure. In a study from Auckland, New Zealand, elderly residents of a rest-home received 15 or 30 min of spring sunlight exposure to the head, neck, forearms and lower legs daily (Reid et al. 1986). Circulating levels of $25(\mathrm{OH}) \mathrm{D}$ rose progressively in both groups and at the end of the 4-week period of study the mean level in the $30 \mathrm{~min} / \mathrm{d}$ group had risen by about $30 \%$.

\section{Effect of ageing on vitamin $D$ metabolism and action}

Of the two sequential hydroxylation reactions of vitamin $\mathrm{D}$ to $25(\mathrm{OH}) \mathrm{D}$ and $1,25(\mathrm{OH})_{2} \mathrm{D}$, only the latter is influenced by age. The possibility of an age-related decline in renal production of $1,25(\mathrm{OH})_{2} \mathrm{D}$ was first indicated by the study of Slovik et al. (1981) who showed that the ability of elderly osteoporotic patients to produce $1,25(\mathrm{OH})_{2} \mathrm{D}$ in response to parathyroid hormone (PTH) was markedly impaired. In a later PTH response study, specifically designed to test age effects, Tsai et al. (1984) produced further evidence that the ability of the kidney to synthesize $1,25(\mathrm{OH})_{2} \mathrm{D}$ declines with age. This decline in renal hydroxylating capacity is entirely compatible with an age-related decline in renal function rather than a specific defect in the enzymic activity of the $25(\mathrm{OH}) \mathrm{D} 1 \alpha$-hydroxylase $(E C$ 1.14.13.13) per se (Silverberg et al. 1996).

In addition to the decreasing ability with age to synthesize $1,25(\mathrm{OH})_{2} \mathrm{D}$, there is evidence for an intestinal resistance to the action of this hormone (Eastell et al. 1991). The mechanism of this intestinal resistance is unclear but could be due to an age-related decrease in the concentration of intestinal VDR as supported by measurements in intestinal biopsies from women (Ebeling et al. 1992).

\section{Hypotheses relating vitamin $D$ deficiency or malfunction to osteoporosis}

Several lines of evidence suggest a role for suboptimal vitamin D status as a possible contributory cause of bone loss in the elderly. Simple measurements of serum levels of $25(\mathrm{OH}) \mathrm{D}$ or $1,25(\mathrm{OH})_{2} \mathrm{D}$ are of limited value in defining vitamin $\mathrm{D}$-deficient states because of the complexity of their interpretation. Measurements of $25(\mathrm{OH}) \mathrm{D}$ require carefullycontrolled assays and reference values that are appropriate for the season and population. When such criteria are met, Lips (1994) noted a progressive downward trend in 25(OH)D 
levels in four groups from healthy young adults, to elderly people living independently, to institutionalized elderly, and elderly patients with hip fractures. A similar general trend to low levels of $25(\mathrm{OH}) \mathrm{D}$ in the elderly and osteoporotics have been found by others. The interpretation of $1,25(\mathrm{OH})_{2} \mathrm{D}$ levels is more complex, being normally under tighter metabolic control and reflecting several influences such as vitamin D status, renal 25 $(\mathrm{OH}) \mathrm{D} 1 \alpha$-hydroxylase activity, PTH activity and physical mobility. This complexity of influence may explain the lack of consensus with respect to circulating $1,25(\mathrm{OH})_{2} \mathrm{D}$ in fracture patients, with some studies reporting low levels and others finding normal levels (Reid, 1996). This is further illustrated by vitamin D supplementation studies in the elderly that always result in large increases in circulating $25(\mathrm{OH}) \mathrm{D}$ but may elicit no increase (Himmelstein et al. 1990; Chapuy et al. 1992; Heikinheimo et al. 1992), or only a slight increase (Lips et al. 1988), in circulating 1,25(OH) 2 D. Further analysis of this response showed that the increase in $1,25(\mathrm{OH})_{2} \mathrm{D}$ was inversely related to the initial $25(\mathrm{OH}) \mathrm{D}$ level, presumably because only in vitamin $\mathrm{D}$ deficiency is the synthesis of $1,25(\mathrm{OH})_{2} \mathrm{D}$ substratedependent (Lips et al. 1988).

More convincing evidence for the role of sub-clinical vitamin D deficiency in osteoporotic bone loss comes from studies linking vitamin D status with parathyroid function and bone density. Seasonal variations and inverse correlations between serum PTH (highest in winter) and serum 25(OH)D (highest in summer) are known to occur in healthy post-menopausal women (Krall et al. 1989) and in healthy elderly people (Hegarty et al. 1994). Krall et al. (1989) showed that this inverse relationship between PTH and $25(\mathrm{OH}) \mathrm{D}$ was dependent on dietary vitamin $\mathrm{D}$ intake and that daily intakes of at least $5 \mu \mathrm{g}$ were needed to offset the wintertime increase in PTH. Intervention studies with higher daily intakes of vitamin $\mathrm{D}$ have also shown that parathyroid function may be suppressed in elderly subjects by improving their vitamin D status (Chapuy et al. 1987; Lips et al. 1988). The hypothesis that these changes are significant to bone is strengthened by studies showing that bone density is positively related to serum $25(\mathrm{OH}) \mathrm{D}$ and inversely related to serum PTH (Khaw et al. 1992; Rosen et al. 1994). As shown by Rosen et al. (1994) there is a strong seasonal component to these variables with an overall decline in BMD in winter (with lowest serum 25(OH)D and highest PTH) and a modest increase in summer (with highest serum 25(OH)D and lowest PTH). A negative relationship between PTH and BMD has also been found in healthy elderly men (Murphy et al. 1993).

Although the evidence outlined previously points to a role for vitamin D deficiency or altered metabolism in the pathogenesis of osteoporosis, the relative importance of the various factors shown in Table 1 is as yet unclear. The beneficial effect of vitamin D in osteoporosis has usually been thought to be mediated through improved $\mathrm{Ca}$ absorption. However, it is at least feasible that an impairment of other actions of vitamin $\mathrm{D}$ on bone metabolism may be important. An alternative hypothesis is that the alterations in the vitamin D system are not in themselves causative of bone loss but induce alterations in another system such as parathyroid function (Silverberg et al. 1996). This view, whereby PTH is seen as a culprit that induces bone loss in the vitamin D-deficient elderly by increasing bone turnover, has gained ground in recent years (Lips, 1994; Compston, 1995). However, it is possible to argue a completely opposing case that the increases in PTH with age are a compensatory adaptation that helps to protect against bone loss (Silverberg et al. 1996). Whatever the mechanism whereby a suboptimal vitamin D might be seen to exacerbate bone loss, it is at least possible to test practically whether boosting the body stores with vitamin D itself or with an active metabolite has a measurable effect on BMD and/or in preventing fractures. This aspect of vitamin D in bone health is considered next. 


\section{INTERVENTION TRIALS WITH VITAMIN D SUPPLEMENTS}

A number of intervention trials have been carried out to see whether the osteoporotic changes in bone with the ageing process can be halted or slowed by improving the vitamin D status of elderly subjects. Such trials have used either vitamin D itself (with or without Ca supplements), or metabolite forms such as the active hormone 1,25-dihydroxycholecalciferol or $1 \alpha$-hydroxycholecalciferol; the latter being first activated by 25 hydroxylation in the liver. In the sense that supplementation with the metabolically-active form of vitamin D may bypass the metabolic impairment of kidney hydroxylation that may be present in elderly people, $1,25(\mathrm{OH})_{2} \mathrm{D}$ treatment may be considered as hormonereplacement therapy rather than a correction of a nutritional deficiency.

\section{Supplementation with vitamin D: effects on bone mineral density}

The results of several prospective trials using vitamin D supplements (all double-blind, placebo-controlled) have been published in the last 6 years. Most have used daily oral supplements. Usually the main outcome measure has been the change in BMD, although in the larger trials it has been possible to examine the effects on fracture rates. Measurements of $25(\mathrm{OH}) \mathrm{D}$ and PTH have provided the biochemical background against which any changes in bone mass could be assessed, and in particular to follow up the hypothesis that secondary hyperparathyroidism caused by a deficit of vitamin D may be a cause of bone loss in the elderly. Summaries of the protocols and main results of the trials with dietary supplements are shown in Table 2.

In Boston, USA, Dawson-Hughes et al. (1991) showed that giving $10 \mu \mathrm{g}$ vitamin D daily to post-menopausal women reduced the wintertime bone loss from the lumbar spine and over the 1-year study period produced an overall net benefit in BMD at this site. However, there was no net change between treated and placebo groups in the whole-body BMD. On the basis that the spine is mainly trabecular bone and that the whole skeleton is $80 \%$ cortical bone, they suggested that trabecular bone is more sensitive than cortical bone to the effects of vitamin $\mathrm{D}$. The winter and spring levels of $25(\mathrm{OH}) \mathrm{D}$ declined from summer and autumn levels by about $25 \%$ in the placebo group but by only $5 \%$ in the supplemented group. This wintertime fall in $25(\mathrm{OH}) \mathrm{D}$ in the placebo group was matched by a significant rise in their wintertime PTH levels that was not observed in the supplemented group. In a follow-up study, the same researchers tried to define more accurately the optimal dose of vitamin $\mathrm{D}$ needed to minimize the rate of bone loss in postmenopausal women (Dawson-Hughes et al. 1995). This was a 2-year trial in which two groups of post-menopausal women received either $2.5 \mu \mathrm{g}$ or $17.5 \mu \mathrm{g}$ vitamin $\mathrm{D}$ as a daily supplement in addition to their usual average dietary consumption of $2.5 \mu \mathrm{g}$. In contrast to their earlier study the changes in BMD at the spine did not differ between the two groups. However, at the femoral neck, although there was an overall loss in BMD in both groups over the 2-year study, this loss was less in the women given the higher dose of vitamin D. Both groups showed seasonal changes in relative gains during the summer and autumn and losses in winter and spring. In the wintertime, levels of $25(\mathrm{OH}) \mathrm{D}$ declined and PTH rose in the lower-vitamin D-intake group but remained stable in the high-intake group. It was concluded that a total daily intake of $5 \mu \mathrm{g}$ vitamin $\mathrm{D}$ was insufficient to minimize bone loss from the femoral neck in post-menopausal women living at a latitude of $42^{\circ} \mathrm{N}$.

A recent intervention trial from The Netherlands in a more elderly group of postmenopausal women has also indicated the positive benefits of vitamin D supplementation (Ooms et al. 1995). After 2 years the vitamin D-supplemented women showed an increase in $\mathrm{BMD}$ at the femoral neck but not at the femoral trochanter and distal radius. Since the 


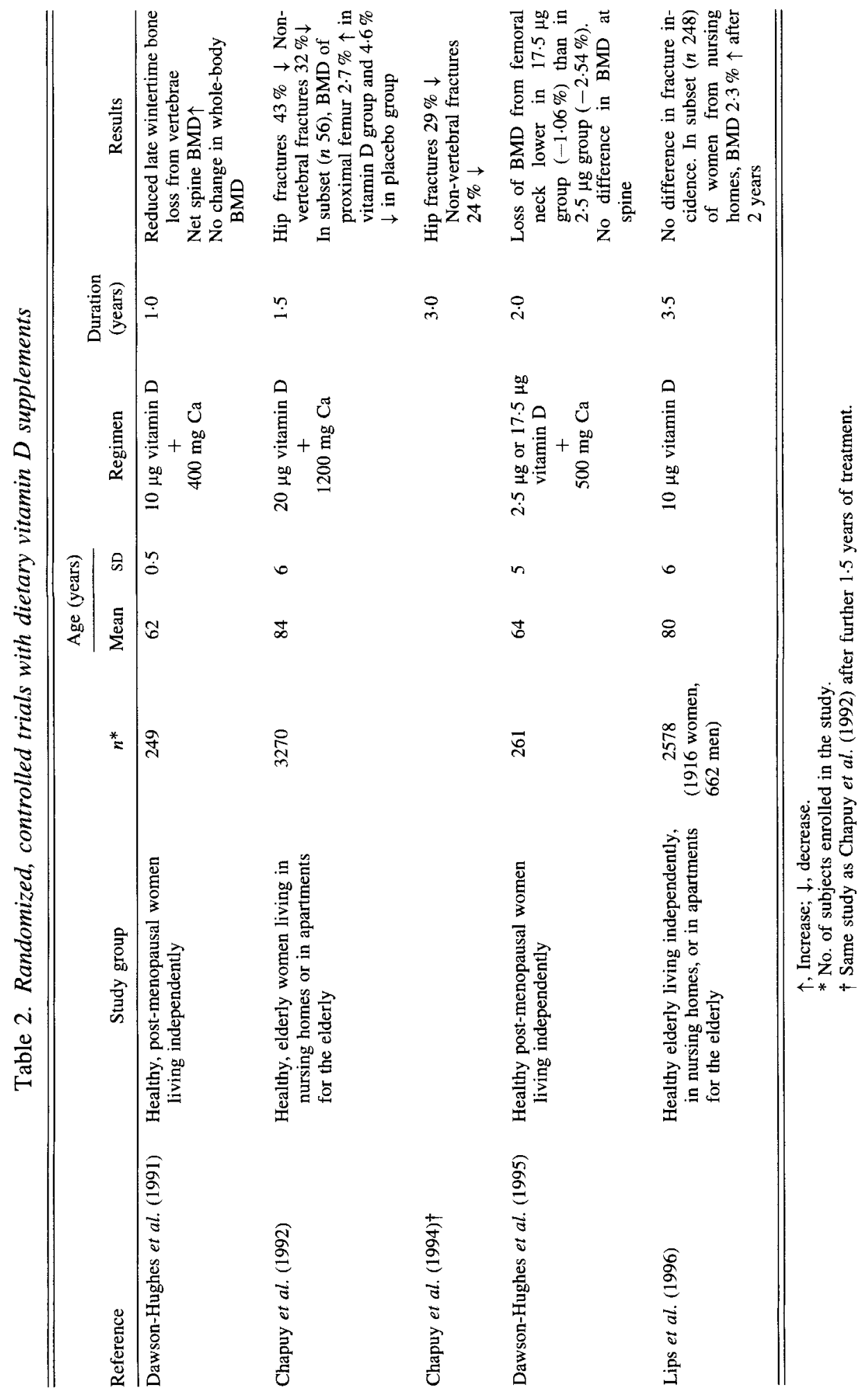


latter sites comprise predominantly trabecular bone, this study does not accord with the original suggestion of Dawson-Hughes et al. (1991) that trabecular bone is more sensitive to the effects of vitamin D than cortical bone. The increase in BMD at the femoral neck was most apparent after the first year of vitamin D supplementation and, as in the studies from the USA (Dawson-Hughes et al. 1991, 1995), was accompanied by significantly increased serum $25(\mathrm{OH}) \mathrm{D}$ and significantly reduced serum PTH.

\section{Supplementation with vitamin D: effects on fracture rates}

Vitamin D supplementation trials from France (Chapuy et al. 1992, 1994) and The Netherlands (Lips et al. 1996) that have been large enough to include fracture incidence as a clinical end-point have shown different results. Thus, whereas the French study (Chapuy et al. 1992, 1994) showed significant decreases in both hip fractures and in total nonvertebral fractures after 1.5 and 3 years, the Dutch study (Lips et al. 1996) showed no difference in fracture rates after 3.5 years (Table 2 ).

What factors could account for these differences? The French subjects receive 1 . higher dose of vitamin $\mathrm{D}$ and extra $\mathrm{Ca}$, their average age was higher and all lived in nursing homes (Chapuy et al. 1992, 1994). In contrast about $40 \%$ of the Dutch cohort were living independently and $25 \%$ were men (Lips et al. 1996). All theoc iaztors were working in a direction that might be expected to enhance the effect of vitamin D in the French study (Chapuy et al. 1992, 1994) and to decrease it in the Dutch study (Lips et al. 1996). The benefits in the French study (Chapuy et al. 1992, 1994) were supported by densitometric measurements made in a subset of fifty-six women showing a $2.7 \%$ increase in BMD of the total proximal femur in the supplemented group compared with a $4.6 \%$ decline in the placebo group. This was mirrored by a $44 \%$ decrease and $12 \%$ increase in serum PTH in the supplemented and placebo groups respectively. These results support the hypothesis that suppression of PTH secretion by correction of a pre-existing vitamin D deficiency may be the chief mechanism underlying the beneficial effect of vitamin $\mathrm{D}$ supplementation on $\mathrm{BMD}$ in the elderly. However, it does not answer the question as to what degree the decrease in fracture incidence may have been mediated by an increase in bone density or by an improved neuromuscular function leading to fewer falls. As in the Fiench stur $y$ (Chapuy et al. 1992, 1994), a sub-study in 248 women from the Dutch trial (Lins $e t$ al. 1996) showed that vitamin D supplementation prevented bone loss; after 2 years active treatment, the BMD at the left and right femoral necks had increased by an average of $2.3 \%$ (Ooms et al. 1995). Again the increased BMD in the Dutch cohort was accompanied by a significant decrease in PTH and, in contrast to the French study (Chapuy et al. 1992, 1994), there was a slight but significant increase in $1,25(\mathrm{OH})_{2} \mathrm{D}$. The authors of the Dutch trial (Lips et al. 1996) gave two main reasons why the positive effects on BMD might not have been seen or did not translate into fracture benefit. First, the original power of the study would have detected a $20 \%$ hip fracture decrease but might have missed the theoretically-predicted $15 \%$ decrease in hip-fracture incidence based on the BMD increase actually found. Second, the sub-set on whom BMD measurements were made were all women living in homes for the elderly and were not representative of the larger fracturestudy cohort that contained men and persons living independently.

Instead of daily oral supplements of vitamin $D$, one prospective trial in Finland investigated the effect of giving a single large dose annually by intramuscular injection for 2-5 years (Heikinheimo et al. 1992). Analysis of all fractures showed significantly fewer in the treated group but, somewhat surprisingly, this reduction only attained statistical significance for fractures of the upper limb with no discernible protection against hip 
fractures. As expected, the fracture rate was much greater in women than men and perhaps because of the small number of male fractures, the effect of vitamin $D$ on fracture reduction was only seen in women.

In conclusion, the trials conducted to date suggest that vitamin D supplements may be beneficial in reducing fracture rates in the elderly, particularly in women living in residential care in northern latitudes. Whether a reduction in fracture rate was shown or not, the mechanical plausibility of a vitamin $\mathrm{D}$ effect is supported by the amelioration in bone loss and the biochemical plausibility by increases in serum $25(\mathrm{OH}) \mathrm{D}$ and decreases in PTH. For oral supplementation, the question of the optimal dose is still unclear. If the average dietary intake is $2.5 \mu \mathrm{g} / \mathrm{d}$ an additional amount of $2.5 \mu \mathrm{g} / \mathrm{d}$ is clearly too low (Dawson-Hughes et al. 1995), but any difference between 10 and $20 \mu \mathrm{g} / \mathrm{d}$ is arguable (Lips et al. 1996). The role of $\mathrm{Ca}$ supplements is also uncertain and needs to be addressed (Compston, 1995).

\section{Supplementation with vitamin $D$ metabolites}

To date only two vitamin $\mathrm{D}$ metabolites $1,25(\mathrm{OH})_{2} \mathrm{D}$ (calcitriol) and $1 \alpha(\mathrm{OH}) \mathrm{D}$ (alphacalcidol) have been used in the treatment of post-menopausal osteoporosis. In Europe and the USA nearly all the trials have used calcitriol, whereas alphacalcidol has been widely used in Japan.

The most reproducible effect of calcitriol is in stimulating intestinal $\mathrm{Ca}$ absorption (Reid, 1996). There have been several controlled trials testing the effects on BMD but few large enough or of appropriate design to test the effects on fracture rates. Some of these trials have reported an increase in BMD but some have reported no benefit (for review, see Fujita, 1992, 1996; Reid, 1996). Closer examination of the results suggests that higher doses of calcitriol are more effective with a threshold beneficial dose of about $0.5 \mu \mathrm{g} / \mathrm{d}$ (Fujita, 1992; Bikle, 1994; Dawson-Hughes, 1996). In studies showing a positive effect on $\mathrm{BMD}$, there is also an indication that the greatest benefit is seen at the spine rather than the hip or radius (Dawson-Hughes, 1996). The effect of calcitriol in reducing fracture rates needs to be confirmed because many of the studies have inherent weaknesses in design (Dawson-Hughes, 1996; Reid, 1996).

The controlled trials with alphacalcidol, mostly carried out in Japan, have shown more consistent benefits on bone mass and/or fracture than calcitriol (Reid, 1996). It seems unlikely that this is an inherent property of this compound because its hepatic conversion to $1,25(\mathrm{OH})_{2} \mathrm{D}$ takes place rapidly after its administration. It is more likely that the apparent greater effectiveness of alphacalcidol reflects either a dose effect or its use in mainly Japanese women who have low $\mathrm{Ca}$ intakes. Thus, the main benefit of either calcitriol or alphacalcidol may be to promote $\mathrm{Ca}$ absorption in populations in whom the availability of dietary $\mathrm{Ca}$ is a limiting factor to bone growth (Fujita, 1992; Reid, 1996).

The medical concerns of the use of calcitriol or alphacalcidol stem from the associated risk of hypercalcaemia, hypercalciuria, and possibly renal calcification (Fujita, 1992; Reid, 1996). Therefore, the balance of achieving an increase in BMD without unwanted side effects may depend on maintaining a delicate balance of the metabolite dose and dietary intake of Ca (Fujita, 1992, 1996).

In summary, the available evidence suggests that vitamin D metabolites may be useful in the treatment of osteoporosis, but that there is a narrow safety margin between benefit and toxicity (Bikle, 1994; Dawson-Hughes, 1996). It is also an area of substantial controversy. The potential therapeutic benefits need to be considered with specific reference to the individuals or population group in whom their use is proposed, and in the 
knowledge that osteoporosis is a heterogeneous condition with a variety of pathogenic origins (Reid, 1996). Ideally the proper use of vitamin D metabolites requires an understanding of their mechanism of action. It is usually assumed that the beneficial effects of vitamin D metabolites accrue from their well-established effects in promoting intestinal $\mathrm{Ca}$ absorption but this is far from certain (Bikle, 1994; Dawson-Hughes, 1996). It should be remembered too that even if a specific defect (e.g. Ca absorption) is corrected, this will not necessarily result in a benefit on bone density (Reid, 1996). Again, if the effectiveness of these agents lies in the correction of an underlying vitamin D-deficient state, as is consistently found in very elderly and frail women, then it is safer and cheaper to treat them with physiological doses of vitamin D (calciferol) than their metabolites (Reid, 1996).

\section{VITAMIN K: SOURCES OF VITAMIN K}

\section{Dietary sources}

The major dietary source of vitamin $\mathrm{K}$ is the plant form phylloquinone. Although phylloquinone is widely distributed in foods, green vegetables contain the highest concentrations (Booth et al. 1995a; Shearer et al. 1996) and represent the single largest contributor to dietary intakes (Booth et al. 1996). In general, the relative phylloquinone content of vegetables reflects its association with photosynthetic tissues, with the highest values $(3-6 \mathrm{mg} / \mathrm{kg}$ ) being found in dark-green, leafy vegetables such as kale (Brassica oleracea acephala), parsley (Petroselinum crispum), spinach (Spinacia oleracea) and cabbage and intermediate amounts (1-2 mg/kg) in broccoli, Brussels sprouts (Brassica oleracea gemmifera) and lettuce. Certain vegetable oils (e.g. soyabean, rapeseed and olive oils) are also relatively rich sources $(0.5-2 \mathrm{mg} / \mathrm{kg})$ and make significant contributions to the diet in margarines and composite foods or when otherwise used for culinary purposes.

The contribution of long-chain menaquinones (MK) to the human diet seems to be limited to a few fermented foods such as cheeses and mainly limited to two major forms MK-8 and MK-9 at concentrations of 50-100 and 100-200 $\mu \mathrm{g} / \mathrm{kg}$ respectively; these are thought to derive from the bacterial starter fermentation, because moulds do not synthesize MK (M. J. Shearer and A. Bach, unpublished results). The only animal food products containing nutritionally significant amounts of long-chain $\mathrm{MK}$ are livers of ruminant species that may contain MK-7-13 at concentrations in the range of $100-200 \mu \mathrm{g} / \mathrm{kg}$. However, long-chain MK are very lipophilic and are likely to be poorly absorbed. MK-4 is atypical of the MK series because it is not a common bacterial form but may be present in animal tissues as a result of its synthesis from menadione, or as recent evidence suggests (Thijssen \& Drittij-Reijnders, 1994), from phylloquinone itself. The nutritional significance of MK-4 still needs to be evaluated because of the widespread use of menadione salts as an animal feed additive that may enhance the natural MK- 4 content of tissues. Some animal tissues and eggs may contain more MK-4 than phylloquinone.

\section{Bacterial synthesis of vitamin $K$ by human intestinal flora}

Many bacteria present in the human intestine synthesize MK and quantitative measurements of their concentrations at different sites have been made by Conly \& Stein (1992). The majority of this MK content is present in the distal colon, with MK-10 predominating. However, there is no direct evidence that this potentially large pool of approximately $1 \mathrm{mg}$ colonic $\mathrm{MK}$ is bioavailable. Evidence against significant colonic absorption is that the highly lipophilic MK are tightly bound to the cytoplasmic membrane and in the absence of bile salts the only perceivable mechanism of absorption would be via 
the portal route (Shearer et al. 1996). Experiments in rats have shown that whereas some colonic MK-4 may be absorbed via the portal pathway, there is no detectable transfer of long-chain forms such as MK-9 (Ichihashi et al. 1992). On the other hand, the widespread presence in the human liver of very-long-chain forms such as MK-10-13, often at higher concentrations than phylloquinone, does require an explanation. It seems likely that MK$10-13$ are of intestinal origin, because they have not been detected in commonly-eaten foods but are typical of the anaerobic genus Bacteroides that are major inhabitants of the intestinal tract. The most likely site of absorption would be the terminal ileum where there are still both reasonable concentrations of MK (Conly \& Stein, 1992) and bile salts.

\section{ACTIONS AND METABOLISM OF VITAMIN K}

The only unequivocal biochemical role for vitamin $\mathrm{K}$ is as a cofactor for a unique posttranslational chemical modification confined to a small group of specialized Ca-binding proteins (Furie \& Furie, 1990). The nature of this modification was first shown in 1974 for the hepatic synthesis of prothrombin (factor II) and soon extended to the other classical vitamin K-dependent coagulation factors VII, IX and X. The vitamin K-dependent step is a carboxylation reaction that transforms selective glutamic (Glu) residues in the protein precursor into $\gamma$-carboxyglutamic acid (Gla) residues. The reaction is catalysed by a microsomal enzyme called $\gamma$-glutamyl or vitamin $\mathrm{K}$-dependent carboxylase (Furie \& Furie, 1990 ) and requires molecular oxygen and $\mathrm{CO}_{2}$. The form of vitamin $\mathrm{K}$ required as the cofactor is not the stable quinone structure found in the diet, but the reduced quinol (or hydroquinone) structure $\left(\mathrm{KH}_{2}\right)$. The subsequent oxidation of vitamin $\mathrm{KH}_{2}$ to vitamin $\mathrm{K}$ 2,3-epoxide provides the energy for the abstraction of a proton from the $\gamma$-carbon of the Glu residue to generate a carbanion that then undergoes carboxylation to yield the final Gla product (Dowd et al. 1995). Within the transformed proteins, the Gla residues confer Cabinding properties and where their function is known (e.g. coagulation proteins) Gla is essential to their biological activity (Furie \& Furie, 1990).

In contrast to vitamin $\mathrm{D}$, no metabolic transformations are thought to be necessary for the post-translational carboxylation role of vitamin $\mathrm{K}$, although the relative importance of phylloquinone and MK in vivo is poorly understood (Suttie, 1995). There are several findings that suggest that long-chain MK (and by implication floral synthesis) are less important than phylloquinone in meeting human requirements. First, even though most of the liver stores comprise long-chain MK, dietary restriction of phylloquinone alone (which would not be expected to alter floral MK availability) can lead to a sub-clinical undercarboxylation of the hepatic coagulation factors (Suttie, 1995). Second, total liver concentrations of MK are much less labile than phylloquinone to low dietary intakes (Usui et al. 1990). This suggests that much of the liver content of long-chain MK might not be readily available to the glutamyl carboxylase. The importance of dietary phylloquinone to the carboxylation status of osteocalcin is suggested by recent findings that show that circulating levels of the under-carboxylated fraction of osteocalcin (ucOC) are responsive to changes in dietary intakes of phylloquinone (Sokoll et al. 1997).

Little is known about the metabolism of vitamin $\mathrm{K}$ in bone. There is one published study of the vitamin $\mathrm{K}$ content of human cortical and trabecular bone which showed the presence of phylloquinone and three MK congeners (MK-6, MK-7 and MK-8) with phylloquinone generally predominating (Hodges et al. 1993b). Preliminary results from our laboratory have confirmed that phylloquinone is the major form in human bone but the MK pattern was different (M. J. Shearer, N. Kakkad and S. J. Hodges, unpublished results). We found only MK-4, $-5,-6$ and -7 in bone lipid; their concentration decreased with the sidechain length and no higher homologue than MK-7 was detected. This pattern is strikingly 
different from the well-established MK spectrum of the liver in which very-long-chain MK (e.g. MK-10-13) usually predominate.

The putative presence of MK-4 in bone is intriguing, because a series of studies from Japan suggest that this congener may have a direct role in inhibiting bone resorption through a different mechanism than $\gamma$-carboxylation. This MK homologue, known as menatetranone in Japan, has been shown to inhibit bone loss in rats, an effect that may be mediated by both the suppression of prostaglandin $\mathrm{E}_{2}\left(\mathrm{PGE}_{2}\right.$ ) synthesis (Hara et al. 1993) and the inhibition of osteoclast-like multinucleated cell formation (Akiyama et al. 1994). Further studies by the same group suggested that this inhibitory effect is specific to the geranylgeranyl side chain of menatetranone and is even displayed by the free alcohol, geranylgeraniol (Hara et al. 1995). More recently, Kameda et al. (1996) presented evidence that MK-4 may inhibit osteoclastic bone resorption by targeting osteoclasts to undergo apoptosis.

\section{Vitamin $K$-dependent bone proteins}

Compared with the well-established role of vitamin $\mathrm{D}$ in bone health, an appreciation that vitamin $\mathrm{K}$ also plays a role in skeletal metabolism came comparatively recently, with the discovery in the mid 1970s that mineralized tissue contained a large reservoir of Gla and that this was associated with at least one major protein (Hauschka et al. 1975; Price et al. 1976). This protein became known as osteocalcin or bone Gla protein (BGP) and accounts for up to $15 \%$ of the non-collagenous bone of vertebrate species (Robey \& Boskey, 1996).

Besides osteocalcin, two other vitamin K-dependent proteins have been isolated from bone tissue: matrix Gla protein (MGP) and protein S (Robey \& Boskey, 1996). Neither protein, however, is exclusive to bone tissue. MGP is also found in cartilage and is expressed by a variety of other soft tissues, while protein $S$ was already known to have an important endothelial function in the feedback control of the coagulation cascade. The roles of MGP and protein $S$ in bone metabolism are uncertain (Binkley \& Suttie, 1995; Vermeer et al. 1995). However, the original suggestion of Price (1985) that MGP may inhibit cartilage mineralization has been strongly supported by the recent discovery that gene-targeted mice that lack MGP undergo spontaneous calcification of soft tissues; one consequence of this is inappropriate calcification of various cartilages including the growth plate, leading to short stature, osteopenia and fractures (Luo et al. 1997). With respect to the role of vitamin $K$, it seems likely that the teratogenic effect of warfarin in causing excessive fetal calcification is at least partly due to the inhibition of MGP function by this vitamin K antagonist (Binkley \& Suttie, 1995). These ill-effects of vitamin K antagonists on bone health seem to be largely confined to rapidly-growing bone. The possible effects of vitamin $\mathrm{K}$ antagonists on adult bone function are controversial, some studies reporting a reduced BMD and others reporting no effect (Binkley \& Suttie, 1995).

\section{Osteocalcin, a vitamin $K$-dependent bone protein modulated by vitamin $D$}

Osteocalcin is a small protein, typically forty-nine or fifty residues, with three Gla residues situated at residues 17, 21 and 24 (Price, 1985). Although there is no homology between osteocalcin and the classical vitamin $\mathrm{K}$-dependent coagulation factors, there has been a high degree of conservation of osteocalcin itself throughout evolution. For example, the position of the three Gla residues in bovine and human osteocalcin are exactly the same as in the swordfish (Xiphias gladius) which diverged from terrestial vertebrates some 400 million years previously (Price, 1985). 
An important physico-chemical property that the three Gla residues confer on osteocalcin is a high adsorption affinity to hydroxyapatite. This affinity to hydroxyapatite is far stronger than that to $\mathrm{Ca}^{2+}$ and seems to be due to the way in which the three Gla residues project outwards from the Gla helix, and their spacing arrangement that complements the interatomic spacing of the $\mathrm{Ca}^{2+}$ of the hydroxyapatite lattice (Hauschka \& Carr, 1982). It has recently been demonstrated that osteocalcin isolated from twenty different human bone specimens is incompletely carboxylated and that the degree of $\gamma$ carboxylation of Glu residues is strongly dependent on their sequence position; the mean values for the percentage $\gamma$-carboxylation at each of the three residues being $67 \%$ at residue $17,88 \%$ at residue 21 and $93 \%$ at residue 24 (Cairns \& Price, 1994). The correlation between the degree of $\gamma$-carboxylation at the two most sensitive glutamate residues of 17 and 21 suggested that the incomplete carboxylation observed in each individual occurred during post-translational modification, possibly due to an insufficiency of vitamin $\mathrm{K}$ in bone cells. Of the adult cohort, although most were elderly (average age 79 years), the incomplete carboxylation reflects the picture in bone matrix synthesized over several years rather than at the time of sampling.

The synthesis of osteocalcin by osteoblasts is modulated by, but not absolutely dependent on, $1,25(\mathrm{OH})_{2} \mathrm{D}$ (Price, 1985). This stimulating effect on osteocalcin synthesis was first observed in vitro in an osteosarcoma cell line (Price \& Baukol, 1980) and later in vivo when the $1,25(\mathrm{OH})_{2} \mathrm{D}$ metabolite was shown to result in a 3-4-fold increase in either young or old rats (Price \& Baukol, 1981). In human subjects too, there is some evidence that circulating osteocalcin levels may be influenced by $1,25(\mathrm{OH})_{2} \mathrm{D}$ but the picture is more complex. Lian \& Gundberg (1988) concluded that while cell-culture and animal studies have shown strong correlations between the effects of $1,25(\mathrm{OH})_{2} \mathrm{D}$ on serum osteocalcin, clinical studies in human subjects have shown a response but not normally a direct correlation. The measurement of circulating osteocalcin has become in its own right one of the most useful clinical biochemical markers of bone turnover and specifically bone formation (Price, 1985; Lian \& Gundberg, 1988).

The function of osteocalcin is unclear. In reviewing the then available evidence, Price (1985) favoured a role as an inhibitor of mineralization. Others, based on early evidence of the chemotactic properties of osteocalcin have favoured a role in skeletal resorption, whereby the protein acts as a matrix signal in the recruitment and differentiation of osteoclasts (Glowacki et al. 1991; Liggett et al. 1994). Chenu et al. (1994) used human osteoclast-like cells from giant cell tumours of bone to demonstrate for the first time that osteocalcin also displays chemotactic activity in a validated human osteoclastic model. They also showed that osteocalcin promoted adhesion and spreading of the osteoclast-like cells followed by the synthesis and release of bone matrix proteins such as osteopontin and bone sialoprotein. Very recently, mutant mice with the osteocalcin gene deleted have been shown to exhibit a phenotype characterized by higher bone mass, with evidence that this was due to an increase in bone formation (Ducy et al. 1996). Both mineralization and resorption appeared normal in the mutant mice, but studies in ovariectomized animals showed a more rapid increase in bone resorption in the osteocalcin-deficient animals compared with the wild-type animals. This suggests that in oestrogen-deficient animals the lack of osteocalcin results in a more rapid bone loss than in normal animals (Ducy et al. 1996).

\section{ASSESSMENT OF VITAMIN K STATUS}

In the last 10 years or so considerable advances have been made in the development of methods which can be used to gain insights into the vitamin $\mathrm{K}$ status of individuals and 
population groups (Shearer, 1995). There have been two main approaches. The first, as with vitamin $\mathrm{D}$, has been to try and assess whether circulating levels of vitamin $\mathrm{K}$ can be used as an index of tissue reserves of the vitamin. The second, more functional approach, is to try and assess the extent of $\gamma$-carboxylation of a target vitamin $\mathrm{K}$-dependent protein. The rationale behind this approach is that a reduced supply of vitamin $K$ will result in the production of under-carboxylated (des- $\gamma$-carboxy) species of the Gla protein that, if also released into the plasma, can be assayed. In practice, although there are many vitamin $\mathrm{K}$ dependent proteins in the body, assays of under-carboxylated species are available for only two proteins, i.e. the coagulation protein prothrombin and the bone protein osteocalcin.

\section{Plasma measurements of vitamin K}

Unlike other fat-soluble vitamins, including vitamin $\mathrm{D}$, reliable methods for the analysis of vitamin $\mathrm{K}$ in plasma and tissues have become available only comparatively recently and their relative complexity has restricted their wider use (Shearer, 1995). Most assays measure only phylloquinone, the predominant dietary and transport form. The measurement of MK-7 and -8 in plasma has been reported in some studies (Hodges et al. 1990, $1991,1993 a$ ).

Vitamin $\mathrm{K}$ has no specific binding protein in plasma and is carried in the circulation by lipoproteins. After an overnight fast, more than half the circulating phylloquinone is still associated with triacylglycerol-rich lipoproteins, thought to be of intestinal rather than hepatic origin, with the remainder being equally distributed between LDL and HDL (Kohlmeier et al. 1996).

Plasma levels of phylloquinone are sensitive to changes in recent dietary intake and in healthy volunteers fall in response to diets that have been moderately (Suttie et al. 1988) or severely (Ferland et al. 1993) depleted in vitamin $\mathrm{K}$. When the dietary intake of phylloquinone was severely depleted from $80 \mu \mathrm{g} / \mathrm{d}$ to about $10 \mu \mathrm{g} / \mathrm{d}$, plasma levels of phylloquinone fell dramatically within a few days to about $15 \%$ of the initial values (Ferland et al. 1993). A similar rapid drop in plasma phylloquinone in response to a low dietary intake (about $5 \mu \mathrm{g} / \mathrm{d}$ ) was observed in hospitalized patients (Usui et al. 1990). A study assessing dietary intakes and plasma phylloquinone in 402 post-menopausal women showed that they were significantly related, although the correlation coefficient $(r 0.13$, $P=0.01$ ) was quite low (Booth et al. 1995b). Stronger relationships between dietary intakes and plasma phylloquinone were obtained in a recent UK study (C. Bolton-Smith, R. J. G. Price, S. T. Fenton, D. J. Harrington and M. J. Shearer, unpublished results).

\section{Assays of under-carboxylated vitamin K-dependent proteins}

Assays for under-carboxylated prothrombin have been available for many years (Widdershoven et al. 1987). However, most lack the sensitivity to detect minor changes in the Gla content of prothrombin. The exception are new generation immunoassays based on monoclonal antibodies to under-carboxylated prothrombin (Widdershoven et al. 1987; Shearer, 1995).

Methods for the assessment of ucOC have been less satisfactory because they have usually relied on an indirect method of assessing the Gla content based on the differential affinity of Gla-rich and Gla-depleted osteocalcin for hydroxyapatite (Price \& Kaneda, 1987; Knapen et al. 1989; Merle \& Delmas, 1990) or for $\mathrm{BaSO}_{4}$ (Sokoll et al. 1995). All these methods suffer from methodological problems that are inherent to osteocalcin assays in general and that relate to the heterogeneity of circulating osteocalcin and its instability in 
serum samples (Blumsohn et al. 1995). Despite these drawbacks there is evidence that these adsorption methods do give useful information about the carboxylation status of osteocalcin in the circulation that reflects the Gla content of newly-synthesized osteocalcin in the bone. Future studies will be helped by the development of a specific assay for ucOC (Vergnaud et al. 1997).

Recent support that ucOC measurements are of value as a marker of vitamin $\mathrm{K}$ nutritional status has come from a study in 263 healthy subjects (aged 18-85 years) from the Boston area that has shown that ucOC is positively correlated with under-carboxylated prothrombin and negatively correlated with plasma phylloquinone (Sokoll \& Sadowski, 1996). The direction of these associations with two established indicators of vitamin $K$ nutritional status are those that would be expected if ucOC was also an index of vitamin $\mathrm{K}$ status.

The value of ucOC measurements as an index of bone vitamin $\mathrm{K}$ status has been underlined by recent findings showing that the proportion of circulating ucOC responds rapidly to reasonably modest changes in dietary intakes of phylloquinone (Sokoll et al. 1997). Thus, when the daily dietary intakes of young, healthy subjects residing in a metabolic ward were increased from $100 \mu \mathrm{g}$ to $420 \mu \mathrm{g}$ the ucOC fraction fell by $41 \%$ after $5 \mathrm{~d}$ and then rose again during the next $5 \mathrm{~d}$ when they returned to the $100 \mu \mathrm{g}$ diet. Interestingly, in a control group who were maintained for the same period on the $100 \mu \mathrm{g}$ diet the percentage of ucOC rose significantly, by $28 \%$. The plasma phylloquinone levels also reflected the dietary changes. One implication of this study is that a large proportion of the population in both the UK (Price et al. 1996) and the USA (Booth et al. 1996) is consuming much less than $100 \mu \mathrm{g} / \mathrm{d}$ and that these intakes are insufficient to keep osteocalcin in a fully-carboxylated state.

\section{VITAMIN K AND OSTEOPOROSIS}

Relatively little is known about the adequacy of the vitamin $\mathrm{K}$ status of different agegroups in relation to bone health. Until recently there has been little reason not to believe that most people, including the elderly, have sufficient dietary intakes of vitamin $\mathrm{K}$. This perception has been based mainly on the extreme rarity of a coagulopathy that can be attributed to a nutritional deficiency of vitamin $\mathrm{K}$. However, with the availability of more sensitive assays for both under-carboxylated prothrombin and ucOC it is now possible to make independent assessments of the sufficiency of vitamin $\mathrm{K}$ in the tissues (liver and bone) that synthesize these two Gla proteins. This has led to the concept of tissue specific requirements for vitamin $\mathrm{K}$ (Vermeer et al. 1995).

\section{Vitamin $K$ status of the elderly: dietary intakes}

With the increasing availability of accurate food data bases for phylloquinone (Booth et al. $1995 a$; C. Bolton-Smith, R. J. G. Price, S. T. Fenton, D. J. Harrington and M. J. Shearer, unpublished results) it is now becoming possible to assess dietary intakes in different population groups. Estimations of dietary intakes of phylloquinone in the US Food and Drug Administration (FDA) Total Diet Study across fourteen age-gender groups suggested that intakes for adults were close to the current US recommended dietary allowances (RDA; National Research Council, 1989) of $80 \mu \mathrm{g}$ for men and $65 \mu \mathrm{g}$ for women, although intakes were slightly lower in the 25-30 years age-group (Booth et al. 1996). The same researchers had earlier reported a much higher average dietary intake of $156 \mu \mathrm{g}$ in 402 healthy post-menopausal women (Booth et al. 1995b). The discrepancy could reflect the 
different methods used to estimate dietary intakes or could be a true reflection of the wide range of dietary intakes in different population groups. In the first detailed study of phylloquinone intakes in the UK, sixty-five Scottish volunteers aged 22-54 years had average daily intakes of 64 and $72 \mu \mathrm{g}$ for men and women respectively (Price et al. 1996). This UK study was based on $7 \mathrm{~d}$ weighed food records made during spring, summer, autumn and winter months and showed no seasonal variation. However, with an intraindividual $\mathrm{CV}$ of $103 \%$, the study showed that there were extreme variations in daily intakes that could easily mask any seasonal trend. The average UK intakes are similar to those reported in the US FDA Total Diet Study (Booth et al. 1996) and close to the current adult dietary reference values for the UK of $1 \mu \mathrm{g} / \mathrm{d}$ per $\mathrm{kg}$ body weight (Department of Health, 1991). However, although the average UK intakes were in line with the guidelines, a significant number of the Scottish population were consuming less than the reference intakes judged to be both safe and adequate. As with the US RDA, they are also based on estimates of the needs to maintain coagulation function (about $1 \mu \mathrm{g} / \mathrm{d}$ per $\mathrm{kg}$ body weight) rather than on any precepts of the needs for optimal bone health. Nothing is yet known about dietary intakes of phylloquinone in an elderly UK population.

\section{Vitamin $K$ status of the elderly: plasma vitamin $K$}

In a study of the factors influencing plasma phylloquinone levels in 326 healthy people from New Mexico, it was observed that there were no sex differences but that young women had significantly lower levels than elderly women (Sadowski et al. 1989). However, when the phylloquinone concentrations were expressed relative to triacylglycerol levels, the picture was reversed and the adjusted values were lower in the elderly of both sexes. This adjustment can be justified on the basis of the strong association of circulating phylloquinone with triacylglycerol (Sadowski et al. 1989; Kohlmeier et al. 1995) and suggests that the elderly may have decreased reserves of phylloquinone. In a small study in the UK, there was no difference in circulating concentrations of phylloquinone or MK-7 between young and elderly healthy individuals, although in the elderly group there appeared to be a deficit of MK-8 (Hodges et al. 1990). However, a similar small French study showed no difference between serum phylloquinone, MK-7 or MK-8 in young and elderly women (Plantalech et al. 1991). Since the validity of measurements of plasma MK, especially MK-8, remain to be established, the significance of this discrepancy between these two studies is at present uncertain.

As illustrated in Fig. 1, plasma measurements made in osteoporotic patients have consistently shown dramatically reduced levels of phylloquinone, and possibly $\mathrm{MK}$, in patients who had sustained femoral neck or spinal crush fractures (Hart et al. 1985; Hodges et al. 1991, 1993a). It has been difficult, however, to assess whether this relationship is fortuitous or causal, but it does not seem to be related to trauma (Hodges et al. 1993a).

\section{Vitamin $K$ status of the elderly: under-carboxylated osteocalcin}

The measurement of circulating ucOC perhaps represents the most relevant marker of vitamin $\mathrm{K}$ with respect to its role in bone health because it provides information on the carboxylation status of a highly abundant vitamin $\mathrm{K}$-dependent protein in bone that is not synthesized in significant amounts by other tissues. The first indication that the elderly tend to have increased levels of ucOC came from a Dutch study comparing osteocalcin measurements in premenopausal (25-40 years) and post-menopausal (55-75 years) women, the latter being recruited from a convent (Knapen et al. 1989). Measurements of 


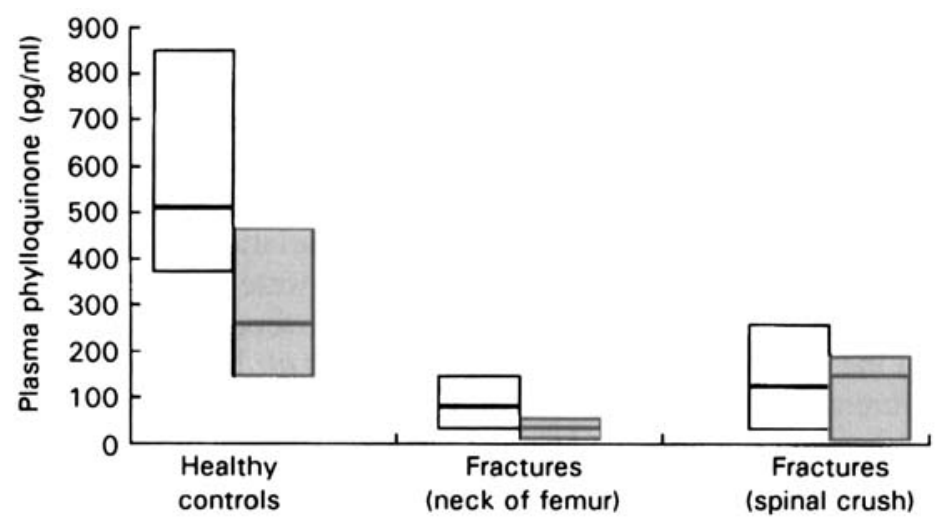

Fig. 1. Circulating levels of phylloquinone $(\square)$ and menaquinone-7 (圆) in patients with osteoporotic fractures of either the neck of femur or spine. Values shown are interquartile ranges and median values $(-)$. (Data taken from Hodges et al. 1991.)

total osteocalcin and the fraction that remained unbound after incubation with hydroxyapatite showed that the percentage of bound osteocalcin (termed by these researchers the 'hydroxyapatite-binding capacity') was more than $50 \%$ lower in the postmenopausal women than in the premenopausal group. An age-related impairment in $\gamma$ carboxylation of osteocalcin in women was also suggested by a cross-sectional French study in three age-groups in which it was found that levels of ucOC were significantly increased after the menopause and markedly increased in old age (Plantalech et al. 1991). This increase in the ucOC fraction was separate from the increase in total antigenic osteocalcin after the menopause that has often been reported and was also seen in the French study of Plantalech et al. (1991). The increase in ucOC with age was found whether ucOC was expressed as an absolute concentration or as percentage of total osteocalcin. The very high levels of ucOC seen in the elderly group (in some women ucOC was as high or higher than levels seen in warfarin-treated patients) may have reflected both their particularly great age (average 85 years) and the fact that they were recruited from a retirement home. However, the finding of normal average serum phylloquinone in a subset of the elderly women, while not ruling out a suboptimal vitamin K status, did not suggest a major vitamin $\mathrm{K}$ deficiency in this elderly group (Plantalech et al. 1991). Other reasons could be an age-related impairment of the transport system of vitamin $\mathrm{K}$ to osteoblasts, a defect in the intrinsic osteoblast $\gamma$-carboxylation mechanism or some other resistance to the action of vitamin $K$ that may be analogous to the tissue resistance to vitamin $D$ seen in the elderly.

The large French vitamin D-supplementation study of Chapuy et al. (1992) has also been the setting of a small osteocalcin-based substudy by Szulc et al. (1993) who showed that the relative risk of hip fracture during follow-up was six times higher in institutionalized, elderly women who had an initially raised ucOC value. ucOC was the only biochemical marker in this study that showed any predictive value for hip-fracture risk and was later shown to correlate with hip BMD (Szulc et al. 1994). The subsequent findings by the same group that serum ucOC was also predictive of fracture risk in a much larger cohort of women living independently (Vergnaud et al. 1997) strengthens the significance of their earlier studies and shows the potential value of ucOC measurements in the assessment of hip-fracture risk. Although vitamin $\mathrm{K}$ deficiency seems the most likely cause of a raised ucOC, unexpected findings were the inverse relationship between serum 
ucOC and $25(\mathrm{OH}) \mathrm{D}$ and the significant lowering of ucOC by vitamin D supplementation (Szulc et al. 1993). This remains unexplained but raises the possibility of an influence of vitamin D on vitamin K-dependent carboxylation through an unknown mechanism.

\section{Effects of vitamin $K$ supplementation on biomarkers of bone metabolism}

Part of the Dutch study demonstrating the age-related changes in the hydroxyapatitebinding capacity of osteocalcin (Knapen et al. 1989) consisted of a supplementation study with a daily dose of $1 \mathrm{mg}$ phylloquinone for 2 weeks. While phylloquinone had no effect on osteocalcin in young women, the proportion of ucOC in post-menopausal women rose substantially to near normal values. There was also a rise in serum levels of total immunoreactive osteocalcin in the post-menopausal group. Moreover, in a subset of about $20 \%$ of the post-menopausal women, classified as 'fast losers' of Ca with evidence of increased bone turnover, there was a substantial and significant decrease in both urinary $\mathrm{Ca}$ and hydroxyproline excretion. The effect of $1 \mathrm{mg}$ phylloquinone/d in decreasing urinary $\mathrm{Ca}$ excretion in post-menopausal women with initially high $\mathrm{Ca}$ output was seen in a second study (Knapen et al. 1993).

In Japan, a large intervention trial in osteoporotic women has been carried out with large doses ( $45 \mathrm{mg} / \mathrm{d}$ ) of MK-4 (menatetranone) with encouraging results, as judged from measurements of BMD and markers of bone turnover. The detailed results of this study carried out by Orimo and co-workers are available only in abstract form in English language journals but have been discussed in the reviews of Binkley \& Suttie (1995) and Vermeer et al. (1995).

\section{CONCLUSIONS}

In the last few years there has been growing evidence that a suboptimal status of vitamin $D$ or vitamin $\mathrm{K}$ may contribute to the pathogenesis of osteoporosis. To date the evidence of a beneficial effect of these vitamins is much stronger for vitamin D for which the results of intervention trials with supplements have been encouraging. There are also plausible mechanisms to explain both the origins and ill effects of a suboptimal vitamin D status, and the benefits of supplementation to bone mass. Comparable compelling evidence of the beneficial effects of vitamin $\mathrm{K}$ to osteoporosis is currently lacking. The potential relevance is based on findings of biochemical indicators of an impaired vitamin $K$ status in osteoporotic patients or to associations of markers of vitamin $\mathrm{K}$ status and those of bone turnover. At the nutritional and biochemical level there is now good evidence that the dietary intakes of vitamin $\mathrm{K}$ needed to sustain maximal carboxylation of bone Gla protein such as osteocalcin are substantially higher than those needed for carboxylation of the coagulation Gla proteins synthesized in the liver (Vermeer et al. 1995; Sokoll et al. 1997). This knowledge together with clinical evidence, such as the increased fracture risk associated with a raised ucOC, is already compelling enough to warrant intervention studies with vitamin $\mathrm{K}$ of similar designs to those already carried out with vitamin $\mathrm{D}$. Thus far, the only vitamin $\mathrm{K}$ supplementation studies carried out have been in Japan with pharmacological doses of MK-4, a form that is not a major dietary component but for which there is nevertheless evidence of a tissue specific distribution and of having antiresorptive properties in bone. The field is still hampered by the lack of knowledge of the physiological function of the vitamin K-dependent proteins in bone and of other possible mechanisms whereby vitamin $\mathrm{K}$ can improve bone mass and/or quality. 


\section{REFERENCES}

Akiyama, Y., Hara, K., Tajima, T., Murota, S. \& Morita, I. (1994). Effect of vitamin $K_{2}$ (menatetrenone) on osteoclast-like cell formation in mouse bone marrow cultures. European Journal of Pharmacology 263, 181185.

Balsan, S., Garabedian, M. \& Lavchet, M. (1986). Long term nocturnal calcium infusions can cure rickets and promote normal mineralization in hereditary resistance to 1,25 -dihydroxyvitamin $\mathrm{D}_{3}$. Journal of Clinical Investigation 77, 1661-1667.

Barragry, J. M., France, M. W., Corless, D., Gupta, S. P., Switala, S., Boucher, B. J. \& Cohen, R. D. (1978). Intestinal cholecalciferol absorption in the elderly and in younger adults. Clinical Science and Molecular Medicine 55, 213-220.

Bikle, D. D. (1994). Role of vitamin D, its metabolites and analogs in the management of osteoporosis. Rheumatic Disease Clinics of North America 20, 759-775.

Binkley, N. C. \& Suttie, J. W. (1995). Vitamin K nutrition and osteoporosis. Journal of Nutrition 125, 18121821.

Blumsohn, A., Hannon, R. A. \& Eastell, R. (1995). Apparent instability of osteocalcin in serum as measured with different commercially available immunoassays. Clinical Chemistry 41, 318-322.

Booth, S. L., Pennington, J. A. T. \& Sadowski, J. A. (1996). Food sources and dietary intakes of vitamin K-1 (phylloquinone) in the American diet: data from the FDA Total Diet Study. Journal of the American Dietetic Association 96, 149-154.

Booth, S. L., Sadowski, J. A. \& Pennington, J. A. T. (1995a). Phylloquinone (vitamin $\mathrm{K}_{1}$ ) content of foods in the U.S. Food and Drug Administration's Total Diet Study. Journal of Agricultural and Food Chemistry 43, 1574-1579.

Booth, S. L., Sokoll, L. J., O'Brien, M. E., Tucker, K., Dawson-Hughes, B. \& Sadowski, J. A. (1995b). Assessment of dietary phylloquinone intake and vitamin $\mathrm{K}$ status in postmenopausal women. European Journal of Clinical Nutrition 49, 832-841.

Bouillon, R. (1990). Clinical use of vitamin D metabolite assays (calcidol and calcitriol). In Calcium Regulating Hormones, Vitamin D Metabolites, and Cyclic AMP: Assays and their Clinical Application, pp. 24-47 [H. Schmidt-Gayk, F. P. Armbruster and R. Bouillon, editors]. Berlin: Springer-Verlag.

Cairns, J. R. \& Price, P. A. (1994). Direct demonstration that the vitamin K-dependent bone Gla protein is incompletely $\gamma$-carboxylated in humans. Journal of Bone and Mineral Research 9, 1989-1997.

Chapuy, M.-C., Arlot, M. E., Delmas, P. D. \& Meunier, P. J. (1994). Effect of calcium and cholecalciferol treatment for three years on hip fractures in elderly women. British Medical Journal 308, 1081-1082.

Chapuy, M.-C., Arlot, M. E., Duboeuf, F., Brun, J., Crouzet, B., Arnaud, S., Delmas, P. D. \& Meunier, P. J. (1992). Vitamin $\mathrm{D}_{3}$ and calcium to prevent hip fractures in elderly women. New England Journal of Medicine 327, 1637-1642.

Chapuy, M.-C., Chapuy, P. \& Meunier, P. J. (1987). Calcium and vitamin D suplements: effects on calcium metabolism in elderly people. American Journal of Clinical Nutrition 46, 324-328.

Chenu, C., Colucci, S., Grano, M., Zigrino, P., Barattolo, R., Zambonin, G., Baldini, N., Vergnaud, P., Delmas, P. D. \& Zallone, A. Z. (1994). Osteocalcin induces chemotaxis, secretion of matrix proteins, and calciummediated intracellular signaling in human osteoclast-like cells. Journal of Cell Biology 127, 1149-1158.

Compston, J. E. (1995). The role of vitamin D and calcium supplementation in the prevention of osteoporotic fractures in the elderly. Clinical Endocrinology 43, 393-405.

Conly, J. M. \& Stein, K. (1992). Quantitative and qualitative measurements of K vitamins in human intestinal contents. American Journal of Gastroenterology 87, 311-316.

Dawson-Hughes, B. (1996). Calcium, vitamin D and vitamin D metabolites. In Osteoporosis 1996: Proceedings of the 1996 World Congress on Osteoporosis Amsterdam. The Netherlands, 18-23 May, 1996, pp. 299-303 [S.E. Papapoulos, P. Lips, H. A. P. Pols, C. C. Johnston and P. D. Delmas, editors]. Amsterdam: Elsevier.

Dawson-Hughes, B., Dallal, G. E., Krall, E. A., Harris, S., Sokoll, L. J. \& Falconer, G. (1991). Effect of vitamin D supplementation on wintertime and overall bone loss in healthy postmenopausal women. Annals of Internal Medicine 115, 505-512.

Dawson-Hughes, B., Harris, S. S., Krall, E. A., Dallal, G. E., Falconer, G. \& Green, C. L. (1995). Rates of bone loss in postmenopausal women randomly assigned to one of two dosages of vitamin D. American Journal of Clinical Nutrition 61, 1140-1145.

Department of Health (1991). Dietary Reference Values for Food Energy and Nutrients for the United Kingdom. Report on Health and Social Subjects no. 41. London: H.M. Stationery Office.

Dowd, P., Hershline, R., Ham, S. W. \& Naganathan, S. (1995). Vitamin K and energy transduction: a base strength amplification mechanism. Science 269, 1684-1691.

Ducy, P., Desbois, C., Boyce, B., Pinero, G., Story, B., Dunstan, C., Smith, E., Bonadio, J., Goldstein, S., Gundberg, C., Bradley, A. \& Karsenty, G. (1996). Increased bone formation in osteocalcin-deficient mice. Nature 382, 448-452.

Eastell, R., Yergey, A. L., Vieira, N. E., Cedel, S. L., Kumar, R. \& Riggs, B. L. (1991). Interrelationship among vitamin $\mathrm{D}$ metabolism, true calcium absorption, parathyroid function, and age in women: evidence of an age- 
related intestinal resistance to 1,25-dihydroxyvitamin D action. Journal of Bone and Mineral Research 6, 125-132.

Ebeling, P. R., Sandgren, M. E., DiMagno, E. P., Lane, A. W., DeLuca, H. F. \& Riggs, B. L. (1992). Evidence of an age-related decrease in intestinal responsiveness to vitamin $D$ : relationship between serum 1,25dihydroxyvitamin $\mathrm{D}_{3}$ and intestinal vitamin $\mathrm{D}$ receptor concentrations in normal women. Journal of Clinical Endocrinology and Metabolism 75, 176-182.

Feldman, D., Malloy, P. J. \& Gross, C. (1996). Vitamin D: metabolism and action. In Osteoporosis, pp. $205-235$ [R. Marcus, D. Feldman and J. Kelsey, editors]. San Diego: Academic Press.

Ferland, G., Sadowski, J. A. \& O'Brien, M. E. (1993). Dietary induced subclinical vitamin K deficiency in normal human subjects. Journal of Clinical Investigation 91, 1761-1768.

Fujita, T. (1992). Vitamin D in the treatment of osteoporosis. Proceedings of the Society for Experimental Biology and Medicine 199, 394-399.

Fujita, T. (1996). Vitamin D in the treatment of osteoporosis revisited. Proceedings of the Society for Experimental Biology and Medicine 212, 110-115.

Furie, B. \& Furie, B. C. (1990). Molecular basis of vitamin K-dependent $\gamma$-carboxylation. Blood 75, 1753-1762.

Glowacki, J., Rey, C., Glimcher, M. J., Cox, K. A. \& Lian, J. (1991). A role for osteocalcin in osteoclast differentiation. Journal of Cellular Biochemistry 45, 292-302.

Hannah, S. S. \& Norman, A. W. (1994). $1 \alpha, 25(\mathrm{OH})_{2}$ Vitamin $\mathrm{D}_{3}$-regulated expression of the eukaryotic genome. Nutrition Reviews 52, 376-382.

Hara, K., Akiyama, Y., Nakamura, T., Murota, S. \& Morita, I. (1995). The inhibitory effect of vitamin $\mathrm{K}_{2}$ (menatetrenone) on bone resorption may be related to its side chain. Bone 16, 179-184.

Hara, K., Akiyama, Y., Tajima, T. \& Shiraki, M. (1993). Menatetrenone inhibits bone resorption partly through inhibition of $\mathrm{PGE}_{2}$ synthesis in vitro. Journal of Bone and Mineral Research $8,535-542$.

Hart, J. P., Shearer, M. J., Klenerman, L., Catterall, A., Reeve, J., Sambrook, P. N., Dodds, R. A., Bitensky, L. \& Chayen, J. (1985). Electrochemical detection of depressed circulating levels of vitamin $\mathrm{K}_{1}$ in osteoporosis. Joumal of Clinical Endocrinology and Metabolism 60, 1268-1269.

Hauschka, P. V. \& Carr, S. A. (1982). Calcium-dependent $\alpha$-helical structure in osteocalcin. Biochemistry 21, 2538-2547.

Hauschka, P. V., Lian, J. B. \& Gallop, P. M. (1975). Direct identification of the calcium-binding amino acid, $\gamma$-carboxyglutamate, in mineralized tissue. Proceedings of the National Academy of Sciences USA 72, 3925-3929.

Heaney, R. P. (1996). Nutrition and risk for osteoporosis. In Osteoporosis, pp. 483-509 [R. Marcus, D. Feldman and J. Kelsey, editors]. San Diego: Academic Press.

Hegarty, V., Woodhouse, P. \& Khaw, K.-T. (1994). Seasonal variation in 25-hydroxyvitamin D and parathyroid hormone concentrations in healthy elderly people. Age and Ageing 23, 478-482.

Heikinheimo, R. J., Inkovaara, J. A., Harju, E. J., Haavisto, M. V., Kaarela, R. H., Kataja, J. M., Kokko, A. M. L., Kolho, L. A. \& Rajala, S. A. (1992). Annual injection of vitamin D and fractures of aged bones. Calcified Tissue International 51, 105-110.

Himmelstein, S., Clemens, T. L., Rubin, A. \& Lindsay, R. (1990). Vitamin D supplementation in elderly nursing home residents increases $25(\mathrm{OH}) \mathrm{D}$ but not $1,25(\mathrm{OH})_{2} \mathrm{D}$. American Journal of Clinical Nutrition 52, 701-706.

Hodges, S. J., Akesson, K., Vergnaud, P., Obrant, K. \& Delmas, P. D. (1993a). Circulating levels of vitamins $\mathrm{K}_{1}$ and $\mathrm{K}_{2}$ decreased in elderly women with hip fracture. Journal of Bone and Mineral Research 8, 1241-1245.

Hodges, S. J., Bejui, J., Leclercq, M. \& Delmas, P. D. (1993b). Detection and measurement of vitamins $\mathrm{K}_{1}$ and $\mathrm{K}_{2}$ in human cortical and trabecular bone. Joumal of Bone and Mineral Research 8, 1005-1008.

Hodges, S. J., Pilkington, M. J., Shearer, M. J., Bitensky, L. \& Chayen, J. (1990). Age-related changes in the circulating levels of congeners of vitamin $\mathrm{K}_{2}$, menaquinone-7 and menaquinone-8. Clinical Science 78, 6366.

Hodges, S. J., Pilkington, M. J., Stamp, T. C. B., Catterall, A., Shearer, M. J., Bitensky, L. \& Chayen, J. (1991). Depressed levels of circulating menaquinones in patients with osteoporotic fractures of the spine and femoral neck. Bone 12, 387-389.

Holick, M. F. (1995). Environmental factors that influence the cutaneous production of vitamin D. American Journal of Clinical Nutrition 61, 638S-645S.

Holick, M. F. (1996). Vitamin D and bone health. Journal of Nutrition 126, 1159S-1164S.

Holick, M. F., Matsuoka, L. Y. \& Wortsman, J. (1989). Age, vitamin D and solar ultraviolet. Lancet ii, 11041105 .

Houston, L. A., Grant, S. F. A., Reid, D. M. \& Ralston, S. H. (1996). Vitamin D receptor polymorphism, bone mineral density, and osteoporotic vertebral fracture: studies in a UK population. Bone 18, 249-252.

Ichihashi, T., Takagishi, Y., Uchida, K. \& Yamada, H. (1992). Colonic absorption of menaquinone-4 and menaquinone-9 in rats. Journal of Nutrition 122, 506-512.

Kameda, T., Miyazawa, K., Mori, Y., Yuasa, T., Shiokawa, M., Nakamaru, Y., Mano, H., Hakeda, Y., Kameda, A. \& Kumegawa, M. (1996). Vitamin $\mathrm{K}_{2}$ inhibits osteoclastic bone resorption by inducing osteoclast apoptosis. Biochemical and Biophysical Research Communications 220, 515-519. 
Khaw, K.-T., Sneyd, M.-J. \& Compston, J. (1992). Bone density parathyroid hormone and 25-hydroxyvitamin D concentrations in middle aged women. British Medical Journal 305, 273-277.

Knapen, M. H. J., Hamulyák, K. \& Vermeer, C. (1989). The effect of vitamin K supplementation on circulating osteocalcin (bone Gla protein) and urinary calcium excretion. Annals of Internal Medicine 111, 1001-1005.

Knapen, M. H. J., Jie, K.-S. G., Hamulyák, K. \& Vermeer, C. (1993). Vitarnin K-induced changes in markers for osteoblast activity and urinary calcium loss. Calcified Tissue International 53, 81-85.

Kohlmeier, M., Salomon, A., Saupe, J. \& Shearer, M. J. (1996). Transport of vitamin K to bone in humans. Journal of Nutrition 126, 1192S-1196S.

Kohlmeier, M., Saupe, J., Drossel, H.-J. \& Shearer, M. J. (1995). Variation of phylloquinone (vitamin $\mathrm{K}_{1}$ ) concentrations in hemodialysis patients. Thrombosis and Haemostasis 74, 1252-1254.

Krall, E. A., Sahyoun, N., Tannenbaum, S., Dallal, G. E. \& Dawson-Hughes, B. (1989). Effect of vitamin D intake on seasonal variations in parathyroid hormone secretion in postmenopausal women. New England Journal of Medicine 321, 1777-1783.

Lian, J. B. \& Gundberg, C. M. (1988). Osteocalcin: biochemical considerations and clinical applications. In Clinical Orthopaedics and Related Research no. 266, pp. 267-291 [M. R. Urist, editor]. Philadelphia: J. P. Lippincott Company.

Lian, J. B. \& Stein, G. S. (1996). Osteoclast biology. In Osteoporosis, pp. 23-59 [R. Marcus, D. Feldman and J. Kelsey, editors]. San Diego: Academic Press.

Liggett, W. H. Jr, Lian, J. B., Greenberger, J. S. \& Glowacki, J. (1994). Osteocalcin promotes differentiation of osteoclast progenitors from murine long-term bone marrow cultures. Journal of Cellular Biochemistry 55, $190-199$.

Lips, P. (1994). Suboptimal vitamin D status: a risk factor for osteoporosis? Advances in Nutritional Research 9 , 151-166.

Lips, P., Graafmans, W. C., Ooms, M. E., Bezemer, P. D. \& Bouter, L. M. (1996). Vitamin D supplementation and fracture incidence in elderly persons: a randomized, placebo-controlled clinical trial. Annals of Internal Medicine 124, 400-406.

Lips, P., Wiersinga, A., van Ginkel, F. C., Jongen, M. J. M., Netelenbos, J. C., Hackeng, W. H. L., Delmas, P. D. \& van der Vijgh, W. J. F. (1988). The effect of vitamin D supplementation on vitamin D status and parathyroid function in elderly subjects. Journal of Clinical Endocrinology and Metabolism 67, 644-650.

Lund, B.\& Sørensen, O. H. (1979). Measurement of 25-hydroxyvitamin D in serum and its relation to sunshine, age and vitamin D intake in the Danish population. Scandinavian Journal of Clinical and Laboratory Investigation 39, 23-30.

Luo, G., Ducy, P., McKee, M. D., Pinero, G. J., Loyer, E., Behringer, R. R. \& Karsenty, G. (1997). Spontaneous calcification of arteries and cartilage in mice lacking matrix GLA protein. Nature 386, 78-81.

MacLaughlin, J. \& Holick, M. F. (1985). Ageing decreases the capacity of human skin to produce vitamin $D_{3}$. Journal of Clinical Investigation 76, 1536-1538.

Marcus, R. (1996). The nature of osteoporosis. In Osteoporosis, pp. 647-659 [R. Marcus, D. Feldman and J. Kelsey, editors]. San Diego: Academic Press.

Merle, B. \& Delmas, P. D. (1990). Normal carboxylation of circulating osteocalcin (Bone Gla protein) in Paget's disease of bone. Bone and Mineral 11, 237-245.

Ministry of Agriculture, Fisheries and Food (1994). Dietary and Nutritional Survey of British Adults: Further Analysis. London: H.M. Stationery Office.

Murphy, S., Khaw, K.T., Prentice, A. \& Compston, J. E. (1993). Relationships between parathyroid hormone, 25-hydroxyvitamin D, and bone mineral density in elderly men. Age and Ageing 22, 198-204.

National Research Council (1989). Recommended Dietary Allowances, 10th ed. Washington, DC: National Academy Press.

Ooms, M. E., Roos, J. C., Bezemer, P. D., Van der Vijgh, W. J. F., Bouter, L. M. \& Lips, P. (1995). Prevention of bone loss by vitamin D supplementation in elderly women: a randomised double-blind trial. Journal of Clinical Endocrinology and Metabolism 80, 1052-1058.

Parfitt, A. M., Gallagher, J. C., Heaney, R. P., Johnston, C. C., Neer, R. \& Whedon, G. D. (1982). Vitamin D and bone health in the elderly. American Journal of Clinical Nutrition 36, 1014-1031.

Plantalech, L., Guillaumont, M., Vergnaud, P., Leclercq, M. \& Delmas, P.D. (1991). Impairment of gamma carboxylation of circulating osteocalcin (bone gla protein) in elderly women. Journal of Bone and Mineral Research 6, 1211-1216.

Prentice, A. (1997). Is nutrition important in osteoporosis? Proceedings of the Nutrition Society 56, $357-367$.

Price, P. A. (1985). Vitamin K-dependent formation of bone Gla protein (osteocalcin) and its function. Vitamins and Hormones 42, 65-108.

Price, P. A. \& Baukol, S. A. (1980). 1,25-dihydroxyvitamin $\mathrm{D}_{3}$ increases synthesis of the vitamin K-dependent bone protein by osteosarcoma cells. Journal of Biological Chemistry 255, 11660-11663.

Price, P. A. \& Baukol, S. A. (1981). 1,25-Dihyroxyvitamin $D_{3}$ increases serum levels of the vitamin Kdependent bone protein. Biochemical and Biophysical Research Communications 99, 928-935.

Price, P. A. \& Kaneda, Y. (1987). Vitamin K counteracts the effect of warfarin in liver but not in bone. Thrombosis Research 46, 121-131. 
Price, P. A., Poser, J. W. \& Raman, N. (1976). Primary structure of the $\gamma$-carboxyglutamic acid-containing protein from bovine bone. Proceedings of the National Academy of Sciences USA 73, 3374-3375.

Price, R., Fenton, S., Shearer, M. J. \& Bolton-Smith, C. (1996). Daily and seasonal variation in phylloquinone (vitamin $\mathrm{K}_{1}$ ) intake in Scotland. Proceedings of the Nutrition Society 55, $244 \mathrm{~A}$.

Reid, I. R. (1996). Vitamin D and its metabolites in the management of osteoporosis. In Osteoporosis, pp. 1169 1190 [R. Marcus, D. Feldman and J. Kelsey, editors]. San Diego: Academic Press.

Reid, I. R., Gallagher, D. J. A. \& Bosworth, J. (1986). Prophylaxis against vitamin D deficiency in the elderly by regular sunlight exposure. Age and Ageing 15, 35-40.

Robey, P. G. \& Boskey, A. L. (1996). The biochemistry of bone. In Osteoporosis, pp. 95-183 [R. Marcus, D. Feldman and J. Kelsey, editors]. San Diego: Academic Press.

Rosen, C. J., Morrison, A., Zhou, H., Storm, D., Hunter, S. J., Musgrave, K., Chen, T., Wei, W. \& Holick, M. F. (1994). Elderly women in northern New England exhibit seasonal changes in bone mineral density and calciotropic hormones. Bone and Mineral 25, 83-92.

Sadowski, J. A., Hood, S. J., Dallal, G. E. \& Garry, P. J. (1989). Phylloquinone in plasma from elderly and young adults: factors influencing its concentration. American Journal of Clinical Nutrition 50, 100-108.

Shearer, M. J. (1995). Vitamin K: its physiological role and the assessment of clinical and subclinical deficiency states. Journal of the International Federation of Clinical Chemistry 7, 88-95.

Shearer, M. J., Bach, A. \& Kohlmeier, M. (1996). Chemistry, nutritional sources, tissue distribution and metabolism of vitamin $\mathrm{K}$ with special reference to bone health. Joumal of Nutrition 126, 1181S-1186S.

Silverberg, S. J., Fitzpatrick, L. A. \& Bilezikian, J. P. (1996). The role of parathyroid hormone and vitamin D in the pathogenesis of osteoporosis. In Osteoporosis, pp. 715-726 [R. Marcus, D. Feldman and J. Kelsey, editors]. San Diego: Academic Press.

Slovik, D. M., Adams, J. S., Neer, R. M., Holick, M. F. \& Potts, J. T. Jr (1981). Deficient production of 1,25dihydroxyvitamin D in elderly osteoporotic patients. New England Journal of Medicine 305, 372-374.

Sokoll, L. J., Booth, S. L., O’Brien, M. E., Davidson, K. W., Tsaioun, K. I. \& Sadowski, J. A. (1997). Changes in serum osteocalcin, plasma phylloquinone, and urinary $\gamma$-carboxyglutamic acid in response to altered intakes of dietary phylloquinone in human subjects. American Journal of Clinical Nutrition 65, 779-784.

Sokoll, L. J., O'Brien, M. E., Camilo, M. E. \& Sadowski, J. A. (1995). Undercarboxylated osteocalcin and development of a method to determine vitamin K status. Clinical Chemistry 41, 1121-1128.

Sokoll, L. J. \& Sadowski, J. A. (1996). Comparison of biochemical indexes for assessing vitamin K nutritional status in a healthy adult population. American Journal of Clinical Nutrition 63, 566-573.

Suda, T., Takahashi, N. \& Martin, T. J. (1992). Modulation of osteoclast differentiation. Endocrine Reviews 13, 66-80.

Suttie, J. W. (1995). The importance of menaquinones in human nutrition. Annual Review of Nutrition 15, 399417.

Suttie, J. W., Mummah-Schendel, L. L., Shah, D. V., Lyle, B. J. \& Greger, J. L. (1988). Vitamin K deficiency from dietary vitamin K restriction in humans. American Journal of Clinical Nutrition 47, 475-480.

Szulc, P., Arlot, M., Chapuy, M.-C., Duboeuf, F., Meunier, P. J. \& Delmas, P. D. (1994). Serum undercarboxylated osteocalcin correlates with hip bone mineral density in elderly women. Journal of Bone and Mineral Research 9, 1591-1595.

Szulc, P., Chapuy, M.-C., Meunier, P. J. \& Delmas, P. D. (1993). Serum undercarboxylated osteocalcin is a marker of the risk of hip fracture in elderly women. Journal of Clinical Investigation 91, 1769-1774.

Teitelbaum, S. L., Tondravi, M. M. \& Ross, F. P. (1996). Osteoclast biology. In Osteoporosis, pp. 61-94 [R. Marcus, D. Feldman and J. Kelsey, editors]. San Diego: Academic Press.

Thijssen, H. H. W. \& Drittij-Reijnders, M. J. (1994). Vitamin K distribution in rat tissues: dietary phylloquinone is a source of tissue menaquinone-4. British Journal of Nutrition 72, 415-425.

Tsai, K.-S., Heath, H. III., Kumar, R. \& Riggs, B. L. (1984). Impaired vitamin D metabolism with aging in women. Journal of Clinical Investigation 73, 1668-1672.

Usui, Y., Tanimura, H., Nishimura, N., Kobayashi, N., Okanoue, T. \& Ozawa, K. (1990). Vitamin K concentrations in the plasma and liver of surgical patients. American Journal of Clinical Nutrition 51, 846852.

Vergnaud, P., Garnero, P., Meunier, P. J., Bréart, G., Kamihagi, K. \& Delmas, P. D. (1997). Undercarboxylated osteocalcin measured with a specific immunoassay predicts hip fracture in elderly women: the EPIDOS study. Joumal of Clinical Endocrinology and Metabolism 82, 719-724.

Vermeer, C., Jie, K.-S. G. \& Knapen, M. H. J. (1995). Role of vitamin K in bone metabolism. Annual Review of Nutrition 15, 1-22.

Widdershoven, J., van Munster, P., De Abreu, R., Bosman, H., van Lith, Th., van der Putten-van Meyel, M., Motohara, K. \& Matsuda, I. (1987). Four methods compared for measuring des-carboxy-prothrombin (PIVKA-II). Clinical Chemistry 33, 2074-2078. 